\title{
APRESENTAÇÃO
}

\section{O PASSADO SABE MUITOS DE NÓS: LABIRINTOS DA OPERAÇÃO HISTORIOGRÁFICA}

DOI: http://dx.doi.org/10.1590/2236-3459/84559

\author{
Maria Stephanou' \\ 'Universidade Federal do Rio Grande do Sul (Ufrgs), Porto Alegre/RS, Brasil \\ Editora de História da Educação
}

$\cos 8$

Le passé sait beaucoup de nous. L'écho entre passé et présent a beau être une évidence, il faut pouvoir le mettre en forme, réfléchir ses manières d'être pensé sans jamais tomber dans la simplification ou quelques anachronismes dérisoires. $\mathrm{La}$ nécessité de travailler en tension semble primordiale. Rien n'est jamais semblable à rien, et l'histoire non seulement ne se répète jamais, mais contient en elle-même la jeunesse et la violence de l'imprévisibilité. Les événements, les grandes orientations, le monde des sentiments ne sont pas invariants. (FARGE, 2011, p. 106). ${ }^{1}$

istória da Educação apresenta-se aos leitores em seu número 55. Podemos ousar uma distração: 55 é número mestre, dá a partida rumo ao futuro. Sugere liberdade, fluência, sagacidade.

"O passado sabe muito de nós", frase que intitula nosso texto, inspira-se na formulação de Arlette Farge. (2011). A autora reporta-se à idéia de que, na busca incessante dos laços entre passado e presente, os documentos palpitam os movimentos de outrora. Ou, ainda, neles se encontram os ruídos persistentes dos tempos. Esses ruídos

\footnotetext{
${ }^{1} \mathrm{O}$ passado sabe muito de nós. O eco entre passado e presente pode bem ser uma evidência, mas é necessário poder materializá-lo, refletir suas maneiras de ser pensado, sem nunca cair na simplificação ou em quaisquer anacronismos insignificantes. A necessidade de trabalhar em tensão parece primordial. Nada é semelhante, e a história não apenas não se repete, mas contém em si mesma a juventude e a violência da imprevisibilidade. Os eventos, as grandes orientações, o mundo dos sentimentos, não são invariantes." (FARGE, 2011, p. 106, tradução livre).
}

\begin{tabular}{|l|l|l|l|l|r} 
Hist. Educ. (Online) & Porto Alegre & v. 22 & n. 55 & maio/ago. 2018 & p. 01-06
\end{tabular}


não são evidentes, é preciso tensioná-los, evitar simplificações mecanicistas e anacronismos, pois em geral, esses ecos podem emergir por furtivos instantes, ou envoltos em outros ruídos, em brumas, opacidades. É preciso dar-se conta e compreender como nossa sociedade aborda os problemas que the sobrevém, suas heranças, alguns intimamente ligados a esses ecos. Mas, afinal, o passado sabe muito de nós, vale reforçar.

Ora, malgrado alguma imprecisão metodológica ou arbitrariedade da comparação, se nos voltarmos a revisitar os artigos dos números de 1 a 54 de nossa revista, ininterruptamente publicados, saberemos muito de nós. Saberemos algo dos movimentos que palpitaram e ainda palpitam no campo da historiografia da educação, no campo editorial dos periódicos científicos do país, nas associações científicas da área, nos itinerários descontínuos de grupos de pesquisa e pesquisadores. O número 1, de abril de 1997, sequer possuía uma Apresentação. Mesmo assim, já lançava aos pesquisadores da área, pautas de atenção inovadoras: Foucault e histórias de vida, relações de gênero, classe social e etnia, o campo religioso, o ensino mútuo no Brasil, o projeto escolanovista no nordeste do país... Passaram-se 21 anos desde então e os ecos entre passado e presente persistem.

Quiçá um lazer cultivado (CORBIN, 2005) venha a dedicar tempo para inventariar o que esses documentos-artigos, supostamente do passado, sabem/contam de nós, não apenas em números, temáticas e nacionalidades dos autores. Mudaram as estações, as teorias e problemas de pesquisa em evidência, as formas de organização da revista, seus suportes e as exigências das métricas de avaliação. O que persistiu? Quais as imprevisibilidades (jovens ou violentas) da revista e do campo? E, sobretudo, quais suas diferentes lógicas ou a multiplicidade de seus tempos? Um estudo-fruição, uma história com prazer (CORBIN, 2005), de História da Educação possivelmente poderia "dar uma atenção a pequenos detalhes" (por exemplo, o primeiro texto-editorial, sob a forma de Apresentação, é publicado em abril de 2003 (v. 7, n. 13 - outro número emblemático), ou atualmente, os novos desafios lançados pelos critérios de indexação dos periódicos na coleção SciELO², que se apresentam às revistas da área. Ou, uma imersão na "ótica compreensiva" de seus editores e autores, mais ainda, e talvez quase inapreensível dada sua complexidade, "os sistemas de representação" do mundo, da história, da educação e dos sistemas educativos que se fazem presentes em suas edições-arquivos. Fica o desafio e o convite para jovens pesquisadores do campo. Talvez uma tese, uma dissertação, um empreendimento de pesquisa. Quem sabe poderão nos levar a conhecer o que "não havíamos levado tão a sério antes”. (BURKE, 2017, p. 24).

Ecos entre o passado e o presente reverberam no número 55, nessa partida a um futuro logo ali... "O historiador tem o dever de não se fechar no passado e refletir assiduamente sobre os problemas de seu tempo", e para isso, haverá de "discernir as diferenças, mas também as semelhanças para afrontar com mais lucidez os perigos de

\footnotetext{
2 Os critérios SciELO, desde meados de 2015, vem incluindo a avaliação dos editoriais dos periódicos, para fins de apuração de sua excelência. Sugere que os editoriais superem o simples arrolamento de artigos publicados a cada número, ou a apresentação genérica e panorâmica de cada edição, de modo a que, em outra direção, formulem ou apresentem análises de temáticas emergentes ou recorrentes, abordagem de controvérsias ou tendências do campo, o exame do estatuto de determinadas teorias ou investigações, balanços analíticos da produção ou balanços de contributos de determinados autores, grupos de pesquisa ou instituições ao campo. Ver: Comunicados do SciELO Brasil aos editores-chefes de periódicos, entre eles o de 08/12/2017. Disponível em: <http://www.scielo.br/avaliacao/Criterios_SciELO_Brasil_versao _revisada_atualizada_outubro_20171206.pdf >.
} 
hoje". (DUBY, 1998).

O dossiê que apresentamos neste número 55 - Estudos sobre o Ensino Secundário no Cone Sul nos anos 1950 e 1960 - organizado por Norberto Dallabrida (Udesc, Santa Catarina, Brasil) e Myriam Southwell (Universidad Nacional de La Plata, Argentina) afirmam claramente a assunção desse dever. Dizem os organizadores: A atual escolarização média apresenta impasses que envolvem a sua democratização quantitativa e a sua atualização pedagógica. [...] Historiadores da educação têm envidado esforços no sentido de compreender a questão a partir de leituras temporais de longa e de média duração". Reunidos os cinco artigos enfeixados por esse desafio, eis que sinalizam para uma reflexão assídua em curso, quiçá potencializada pelo dossiê em diferentes espaços e coletivos do campo da Educação.

Mais agudo parece ser nosso presente, saturado de agoras, segundo a expressão benjaminiana. Robert Darnton, autor de destaque nessa reflexão, enfatiza com perspicácia que

Embora o estudo da história não renda lições que possam ser aplicadas diretamente sobre circunstâncias do presente, a imersão no passado é capaz de proporcionar uma perspectiva útil para eventos do presente e do futuro. (DARNTON, 2010, p. 13).

Às vésperas da eleição presidencial no país, os historiadores da educação, contemporâneos aos acontecimentos, o que têm a pensar? Como poderão, proximamente, narrar os acontecimentos do contemporâneo que escoará? Como a grande mídia e as redes sociais se posicionarão, disseminarão informações e propostas de governo sobre Educação? Quais serão os projetos em disputa? Se o contemporâneo se nos apresenta em sua opacidade, o que podemos registrar, apontar, ter em mente? Quais resíduos e pistas, através de nossa publicação, deixaremos para os que nos sucederão? Que perspectiva - útil - do passado acionaremos para pensar?

A pauta da hora são as assim chamadas fakenews, que aos historiadores interessam não apenas para demonstrar suas omissões, injúrias e calúnias, mas também para ressaltar as verdades que essas "notícias ou informações disseminadas" se esforçam em produzir. Não serão apenas os problemas de autenticidade que se apresentarão num futuro da pesquisa, mas sobretudo os problemas interpretativos, teóricos, o quase inacessível de suas opacidades. As noções de falso e verdadeiro, elas mesmas complexas, estarão em jogo, Como havemos de nos ver no futuro face aos documentos produzidos nesse contexto e diante da necessidade de compreender a profundidade dos processos imbricados? Quais os "efeitos de real" que, o que parece hoje uma novidade, no passado foram notícias falsas e "mentiras" similares? Robert Darnton, em diferentes obras (1995, 2010,2017 ), examina precisamente os precursores do sensacionalismo e das mentiras, em outros tempos, que segundo ele, remontam pelo menos à Idade Antiga, cerca do século VI, quando Procópio, historiador bizantino, escreveu um texto secreto, chamado de "Anekdota", que ele recheou de "fake news", assim comparadas por Darnton (2017), e arruinou a reputação do imperador Justiniano e de outros, similar ao que para o autor teria ocorrido com as últimas eleições americanas. Estará o autor produzindo um anacronismo simplificador? Ou lançando luz sob prismas diferentes, mas muito oportunos para analisar ambos os contextos? Vale pensar, ao menos contrastar e surpreender continuidades ou 
descontinuidades, do que Darnton designa como "armadilhas da mídia". (1995).

A relevância do exame da invenção histórica do que hoje denominamos como "fake news", segundo Darnton (2017) teve como principal difusor Pietro Aretino (1492-1556), que no século XVI desenvolveu uma nova arma, a difamação, para as batalhas políticas. Aretino afixava seus poemas e escritos nas estátuas de um personagem conhecido como Pasquino, perto da Piazza Navona, em Roma. Para Darnton (2017), "ele difamava a cada dia um dos cardeais candidatos a virar papa". Seus escritos, em geral poemas, ficaram conhecidos como "pasquinadas", ataques a figuras públicas. Ou ainda, mais emblemáticos foram, como menciona Darnton, os "homens-parágrafos" da Londres de 1770, indivíduos que recolhiam fofocas e as redigiam em um único parágrafo em pedacinhos de papel, vendidos para impressores e editores, que as imprimiam em forma de pequenas reportagens, muitas vezes difamatórias. (DARNTON, 2012; 2017). Atuavam também na França pré-revolucionária, quando libelos e panfletos formavam, através de difamações, uma crônica escandalosa como a principal versão de uma história. Em Paris, embora de forma mais subterrânea devido à censura à imprensa, os literatura escandalosa vicejou no século XVI. Notícias inventadas, calúnias, intrigas, difamações e injúrias constituem, para o autor, redes difamatórias de comunicação. Para entender essas redes da mídia, seus documentos e práticas, para Darnton, é importante estudar seus autores e o mundo que habitam/habitavam. Mas também podemos deixá-las de lado, qual lixo que se acumula em qualquer época. "Talvez possamos aprender algo sobre as armadilhas da mídia se dermos uma olhada às pilhas de lixo do passado". (DARNTON, 1995). O passado sabe muito de nós...

Em poucas semanas, presenciaremos no país as formas de fazer política, as formas midiáticas de tratar a política e o lugar ocupado por eventuais redes difamatórias, seus danos e efeitos. Alguns, já se fazem sentir como reverberações dos processos eleitorais municipais de 2016, mormente no âmbito dos sistemas públicos de ensino. $A$ persistência dessas redes, "aonde nos levará? Não sei, mas acho que bem precisamos uma mudança de curso". (DARNTON, 1995).

Se o modo de percepção dos acontecimentos tornou-se tão importante quanto os próprios acontecimentos, como nossas sensibilidades são afetadas pelas redes midiáticas contemporâneas? Como elas filtram os ecos do passado e a leitura do presente? Que lugar pode ocupar uma história das sensibilidades no campo de estudos da História da Educação? Duas contribuições são ofertadas aos leitores nesse numero 55. A primeira está na Sessão Especial que contempla uma entrevista com Kira Mahamud Ángulo, da Universidad Nacional de Educación a Distancia (Uned), Madri, concedida à Professora Luciane S. Grazziotin (Unisinos), e intitulada "Os estudos das emoções em manuais escolares do ponto de vista historiográfico". A entrevista oferece elementos de reflexão sobre as indagação antes explicitadas. Soma-se uma segunda contribuição ao debate acerca de "sensibilidades \& operação historiográfica", debatida por Marcus Taborda de Oliveira, que provoca o leitor com os ventos de modismos e ventos de renovação no âmbito da História da Educação.

O número 55 contempla, afinal, um conjunto total de dezessete artigos, expressivos da autoria de 23 autores, além de duas pesquisadoras que apresentam um documento inédito de 1941, da Diretoria de Educação e Saúde Pública de Pelotas, Rio Grande do Sul, cujo objetivo central era regular e normatizar o trabalho de professores e gestores de 
escolas daquele município, com ênfase à Campanha de nacionalização do ensino. Os artigos estão vinculados a pesquisadores de quatro países e mais de uma dezena de instituições de ensino superior.

Destaca-se, em especial, a diversidade cronológica e temática dos artigos de submissão individual, todos examinados segundo as normas da revista, que levou a contar com a inestimável contribuição da avaliação por pares, representada pela atuação de mais de vinte e cinco examinadores, de diferentes filiações e diversidade geográfica.

Os temas em evidencia no conjunto dos artigos abarcam história das idéias e da edição, história de mulheres, literatura feminista, memórias de professoras, infância e exílio, nipo-brasileiros e educação ultranacionalista japonesa, intelectuais e pós-graduação, arquivos e historiadores, museologia, contribuições da micro-história italiana ao campo da história da educação.

Aproveitamos o ensejo para lembrar aos autores e leitores de História da Educação que, a partir deste número 55, passamos a adotar o Orcid como identificador dos autores, uma vez que, segundo as normas SciELO, este passará a ser obrigatório para os periódicos de sua coleção, a partir de janeiro de 2019. Estamos nos antecipando, na expectativa de fomentarmos essa prática em nossa comunidade de pesquisadores, autores e leitores. $O$ Orcid, segundo o SciELO, juntamente com a adoção da publicação de preprints, que estamos projetando para implementação em 2019, aperfeiçoarão as políticas editoriais e se refletirão nos processos de interoperação e bibliométricos que envolvem autores e periódicos. História da Educação prepara-se para acompanhar esses novos movimentos do campo editorial brasileiro, em consonância com seus correspondentes internacionais.

Os leitores, parafraseando Robert Darnton (2012), serão capazes de reconhecer os principais episódios e distinguir a estrutura básica, teórica, conceitual e metodológica de todos os enredos enfeixados por este número de História da Educação, de tal modo que mobilizados por sua contextura mental poderão triar os acontecimentos, as reflexões suscitadas, a visão de mundo formulada. Fica o convite!

\section{Observação a propósito da Capa}

Como publicamos no Editorial do n.54/2018, Gilberto Alves Leal, digital designer, artista visual e pesquisador, foi convidado a criar a capa das edições do ano de 2018, provocado pela intersecção dos temas história, juventudes e movimentos estudantis. A capa evoca os 50 anos de Maio de 1968. Segundo o artista, a obra intitula-se "Anotações de 68", e foi produzida em dezembro de 2017, com desenho criado especialmente para a capa da edição 54 de História da Educação e as demais do ano, incitado pela famosa foto de um estudante de Medicina sendo perseguido por policiais na Cinelândia, Rio de Janeiro, fotografia de autoria de Evandro Teixeira. A foto pode ser acessada em: <https://oglobo.globo.com/cultura/revista-da-tv/as-imagens-marcantes-de-evandroteixeira-feitas-em-1968-21143306>

\section{Referências}

BURKE, Peter. Testemunha ocular. O uso de imagens como evidência histórica. São Paulo: Editora UNESP, 2017. 
CORBIN, Alain. O prazer do historiador. Rev. Bras. Hist. [online], v. 25, n. 49, p.11-31, 2005.

DARNTON, Robert. A questão dos livros: passado, presente e futuro. São Paulo: Companhia das Letras, 2010.

. Armadilha da mídia: redes difamatórias de comunicação existem, há quatro séculos.

Folha de São Paulo. São Paulo, 17/09/1995. p. 10.

O diabo na água benta ou $A$ arte da calúnia e da difamação de Luís XIV a

Napoleão. São Paulo: Cia. das Letras, 2012.

. Entrevista à Folha de São Paulo. Notícias falsas existem desde o século 6, afirma

historiador Robert Darnton. FSP: São Paulo, 19/02/2017. Disponível em: $<$ https://www1.folha.uol.com.br/ilustrissima/2017/02/1859726-noticias-falsas-existem-

desde-o-seculo-6-afirma-historiador-robert-darnton.shtml>.

DUBY, Georges. Ano 1000, ano 2000: na pista de nossos medos. São Paulo: Fundação Editora da UNESP, 1998.

FARGE, Arlette. De la lecture des archives de police du XVIlle siècle à la construction d'objets pour l'histoire. COHEN, Evelyne; GOETSCHEL, Pascale; ORY, Pascal; MARTIN, Laurent (Dirs.). Dix ans d'histoire culturelle. Villeurbanne: Presses de l'enssib, 2011. p. 101-128.

MARIA STEPHANOU é professora Titular da Faculdade de Educação da Universidade Federal do Rio Grande do Sul (Ufrgs). Pesquisadora do CNPq, atua junto ao Programa de Pós-Graduação em Educação na linha de pesquisa História, memória e educação. Doutora em Educação pela Ufrgs, realizou seu pós-doutoramento junto ao Institut Français d'Éducation (IFÉ), França. Atua como editora de História da Educação desde 2011.

Endereço: Rua Dr. João Palombini, 144 A, 91751-150, Porto Alegre/RS, Brasil. E-mail: mastephanou@gmail.com 